\title{
Some remarks on the elaboration of a multilingual specialized dictionary of hippology
}

\author{
Stanislava Galova - Katarina Klimentova - Lubomira Moravcova
}

DOI: 10.18355/XL.2021.14.02.02

\begin{abstract}
Specialized vocabulary is one of the most important and dynamically developing subsystems of a national language. Due to the continuous development within society, most of the subject fields are characterized by considerable variability and terminological inconsistency. One of the possibilities to contribute to more effective and clearer communication is the collection of terms in the form of specialized glossaries and dictionaries. The elaboration of the dictionary is not an easy task. It requires a precise and detailed plan of individual activities and the cooperation of experts and specialists in the field of linguistics and a subject field in question.

The aim of the study is to describe the individual phases of the elaboration of a multilingual specialized dictionary of hippology and to present in more detail the pitfalls of its creation.
\end{abstract}

Key words: terminology, specialized language, specialized lexicography, a specialized dictionary, elaboration of a multilingual specialized dictionary

\section{Introduction}

Every society uses a language that enables communication in the social and economic life of the society. It is considered to be one of the social institutions by means of which the users adapt to its laws and norms. For this reason, it is also an important unifying and integrating phenomenon of any society.

In today's modern world of globalization, specialized communication in individual fields of science, research, and production is becoming increasingly important as a means of exchanging information, knowledge, and experience. It is based on a specialized vocabulary, which is used mainly by specialists in a particular subject field. Intensive international cooperation places an increasing emphasis on the ability to master the specialized vocabulary of a particular subject field in both the mother tongue and the foreign language.

Specialized vocabulary, like the general vocabulary of a particular language, is not a closed system but changes and reflects on societal, political, and economic development. Some terms are being replaced by new ones to express and designate more accurately the concepts of extra-linguistic reality. On the other hand, new terms for existing concepts as well as terms borrowed from foreign languages are increasingly penetrating the terminology of individual disciplines. This leads to considerable variability and terminological inconsistency and does not contribute to the clarity of scientific knowledge and effective specialized communication. Experts and specialists are concerned with the need for more effective and clearer communication. They create mainly electronic glossaries and dictionaries of basic concepts, but rarely in cooperation with linguists. Therefore, there are also words and multi-word expressions in dictionaries and glossaries that are not considered to be terms as they do not meet the characteristics and criteria related to them.

A similar situation can be observed in the field of hippology. Concerning the academic environment in Slovakia, horse breeding is studied mainly by the academic staff and researchers working at the Department of Animal Husbandry of the Slovak University of Agriculture in Nitra (SUA). They closely cooperate with the specialists from practice (National Stud Farm in Topolcianky). Their cooperation has resulted in several books and textbooks for students of hippology, including the textbook 
"Description and Exterior of the Horse". A final part of this textbook consists of a Slovak-Czech-English-German dictionary, which, however, contains only basic terms from certain sub-areas of the subject field in question, mainly anatomy and the exterior of the horse. Concerning the Slovak market, there is no a multilingual specialized dictionary of hippology, which would evenly cover the given issue. This fact was the incentive for the cooperation between the Department of Animal Husbandry and the Department of Languages of the Slovak University of Agriculture in Nitra. The output of their cooperation is a multilingual specialized dictionary of hippology. The aim of the cooperation was to create a specialized dictionary that would significantly contribute to the development of the foreign language competence of both students and specialists from the academic environment and practice, and would significantly help to achieve more effective specialized communication. The implementation of this intention was not easy. In the individual phases of the elaboration of the dictionary, we faced smaller, but more often, bigger problems, especially concerning the extraction of Slovak terminological units and the assignment of appropriate equivalents in individual foreign languages. In cooperation with native and foreign specialists in the field of hippology, we gradually managed to solve the problems and successfully published the dictionary.

The presented study is one of the partial outputs related to the Project KEGA $n^{\circ}$. 005SPU-4/2018 "Slovak-English-French-German-Russian-Spanish Dictionary of Hippology".

The aim of the study is to describe the individual phases of the elaboration of a multilingual specialized dictionary of hippology and to present in more detail the pitfalls of its creation.

\section{Brief introduction of the basic concepts: terminology, specialized language, specialized lexicography, and dictionary}

\section{1) Terminology and specialized language}

In practice, the term terminology refers to two or three concepts. The Slovak School of Terminology also mentions two meanings of the term terminology and tries to distinguish them. In order to avoid ambiguity, linguists often prefer the compound designation, theory of terminology, to denote a linguistic discipline. The word (designation) terminology is understood primarily as a set of specialized terms used in different subject fields of science, production, art etc. However, terminology also means a linguistic discipline, the study of the characteristics, formation, and the use of terms (Masar, 2000: 11-12). In the "Slovak Encyclopedia of Linguistics" (Mistrik et al., 1993), the concept of the theory of terminology is defined more broadly as "the study of designating the concepts in certain disciplines, defining concepts and creating a system of concepts. Its task is to examine the characteristics of terms and develop general principles of their formation and definitions".

Cabré (1993: 82), the most significant Catalan terminologist, gives three meanings of the term terminology. She distinguishes the theory of terminology in the sense of terminology as a science dealing with the study of terms and terminology in the sense of $a$ set of terms in individual fields of science or human activity. However, Cabré also understands terminology as a set of principles and rules that are applied within the terminographic activities.

For the purposes of our research, we understand the terminology as a set of terms used in hippology.

Terminology or specialized vocabulary is one of the characteristic features of specialized language or language for special purposes (LSP). The question of what is meant by a specialized language is still quite difficult to answer as there is no single and clear definition of this concept. The authors have approached this concept from

XLinguae, Volume 14 Issue 2, April 2021, ISSN 1337-8384, eISSN 2453-711X 
very different perspectives. De Beaugrande (1987, cited in Cabre, 1993: 131-135) provides a synthesis of some of the most representative positions:

1. Some authors think that a clear line can be drawn between the general and the specialized in linguistics by considering that specialized languages are linguistic codes but with units and rules that differentiate them from the general language (Hoffmann 1978; Felber, 1986).

2. Another group of authors considers specialized languages as variants of general language (Rondeau 1983; Rey 1979).

3. There are also authors who consider specialized languages as pragmatic subsets of language as a whole, and therefore understand that there is a confluence of part of the characteristics of the general language and another part of its own characteristics (Sager, Dungworth and McDonald 1980; Pitch and Draskau 1985).

Another interesting approach is presented by Bergenholtz and Tarp (1995), who establish a series of possible relations between general and specialized language. They state that, on the one hand, it can be considered that, to a greater or lesser extent, all specialized languages use the system of the general language and can be included in it. On the other hand, from a lexical perspective, it can be understood that all expressions of the general language are also found in specialized languages and, therefore, the general language is a subsystem of specialized languages. Finally, concerning a communicative perspective, it can be understood that general language and specialized languages are used in situations completely different. Thus, the specialized languages and the general language are the same and different phenomena at the same time.

Based on the presented approaches, it can be stated that different characteristics of specialized languages are emphasized by the authors. We maintain the opinion of M. T. Cabré, who states that the best way to define and describe specialized languages is to combine the subject criterion with other pragmatic criteria and conditions, such as the type of user, topic of the communication, situations in which the communication takes place etc. She defines specialized languages as pragmatic variants that are in a relationship of inclusion with regard to the language as a whole and in a relationship of intersection with respect to the general language with which they share characteristics and where there is a constant transfer of units and conventions (Cabre, 1993: 140). This relationship can be represented as follows (Figure 1):

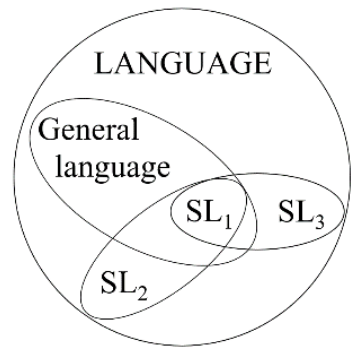

Figure 1: Interrelationship between the language as a whole, general language, and specialized languages (Cabre, 1999: 66)

Thus, the communication (written or oral) within a specific field of knowledge will include units of the general language (i.e. syntax, morphology, and a part of the lexicon used by the majority of speakers of a language) and the subcode that is characteristic of the subject field itself and that contains the specific terminology of the given subject field whose understanding and correct use is the basis of specialized dictionaries. 


\section{2) Specialized lexicography and specialized dictionary}

The foundations of modern specialized lexicography were laid in the 1930s when E. Wüster presented his work on terminology "The theory and practice of the creation, documentation and use of terms". Since then, the interest in specialized language has been steadily growing, as there has been the need for dictionaries explaining this language to the increasing number of field experts and the interested public. (Tihelkova, 2006).

Among the first scholars who put forward a consistent theory of specialized lexicography belonged E. H. Wiegand. He has pursued the goal of establishing lexicography as a discipline in its own right, independent of linguistics. Apart from his interest in general lexicographic issues, Wiegand has written on specialized lexicography. In his article "What exactly specialized lexicography is?" (1998) he has provided a typology of specialized reference works, dividing them into encyclopedias, language dictionaries and encyclopedic dictionaries. This work influenced the next generation of lexicographers. Whereas encyclopedias provide factual information about the subject field, dictionaries give information on the language of the specific field, and encyclopedic dictionaries contain a combination of encyclopedic and linguistic information. E. H. Wiegand himself tends towards multi-functionality of dictionaries and considers the last type of reference work preferable as far as the user's benefit is concerned.

The theories presented by E. H. Wiegand remained unchallenged until a new generation of lexicographers arrived in the mid-1990s, represented by H. Bergenholtz, S. Tarp and S. Nielsen. They have gained an international reputation for introducing fresh ideas into specialized lexicography, especially with respect to dictionary functions and the user-oriented approach. They share Wiegands's view that lexicography represents an independent discipline. Thus, it is not a subfield of lexicology. They also accept that the subject field of lexicography is represented by dictionaries ( man-made products), while the focus of linguistics is language, a system inherent in human beings. Whereas Wiegand's theory looks at lexicography from the point of view of linguistics, the new generation of lexicographers sees a dictionary as a utility product designed to meet particular user needs (Bergenholtz and Tarp, 2003: 171).

Later on, Bergenholtz and Tarp also began to develop the theories of lexicography in terms of specialized dictionaries by introducing a lexicographical approach to the study of terminology, namely LSP lexicography (specialized lexicography).

Within this design, a crucial role is played by practical considerations based on the profile of the target user as well as the situation of use. Nielsen's theoretical contribution consists in introducing several key concepts, including the maximizing vs. minimizing dictionary, the communicative function of a dictionary, and lexicographic information cost. Nielsen (1999) defines a dictionary (printed or electronic) in terms of its major features:

1. A dictionary is a lexicographic reference work compiled to fulfill one or more of its functions (its true potential).

2. It contains lexicographic data supporting the functions.

3. It contains lexicographic structures that combine and link the data in order to fulfill the functions.

In addition to dictionary typology and functions, Nielsen has focused his research on the dictionary cross-reference structure (also called "mediostructure"), and has introduced the concept of function-related cross-references (Fathi, 2015).

The literature on the subject shows two main approaches to the study of dictionaries: functional and communicative. In the functional approach, based on the functional theory of lexicography, dictionaries are studied as the objects of lexicography which

XLinguae, Volume 14 Issue 2, April 2021, ISSN 1337-8384, eISSN 2453-711X 
should meet the needs of target users, including specialized and general dictionaries. In the communicative approach, based on the communicative theory of terminology, terminography is defined as one of the terminology applications in which specialized dictionaries are final products of the process of terminology. These two approaches have been discussed by lexicographers and terminographers for many years. Although considerable efforts have been made to define specialized lexicography and terminography, the borders are still not clearly set. Issues about whether terminography is a part of lexicography or whether terminographers should or should not follow the theoretical bases of lexicography still exist in much recent research (Fathi, 2015).

It seems that debates between lexicographers and terminographers are due to different perspectives, though they talk about a single object when discussing a "specialized dictionary". The idea is not that terminographers should follow the fundamental aspects, nor the methodology, of the functional theory of lexicography. We believe that terminography and specialized lexicography are the same in theory and practice.

The presented theoretical knowledge formed the basis for the elaboration of a multilingual specialized dictionary. Different phases of its creation are described in detail in the following part of the presented study.

\section{Elaboration of the multilingual specialized dictionary of hippology}

Regarding the division of phases of the lexicographic process, there is a significant inconsistency in professional sources. This concerns not only the designation of individual phases, but also their degree of concretization. Some authors perceive the pursuit of transparency and complexity at the same time, the result of which is the merging of several steps to the main phases of the elaboration of dictionaries. As an example, we can mention S.L. Landau's structure (1984) consisting of three phases planning, writing, producing, as well as the 5 phases of creating of the dictionary, presented by H.E. Wiegand et al. (2010: 132): the preparation phase, data collection phase, data editing phase, data analysis phase and the preparation of setting and printing phase. Such division is characterized by a high degree of universality and applies to any lexicographic process.

On the other hand, in some works, we encounter an effort to achieve the highest possible degree of exactness. The result is a detailed division of the lexicographic process into a large number of phases. This situation is illustrated by R. Kocourek (1966), dividing the creation of a bilingual dictionary into more than 20 phases: field study, choice of excerpt text, choice of semantic sources, division of excerpt text into sections, text translation, and excerption of unclear terms, equivalence research, translation revision, text processing and translation for excerption, determination of excerpt principles and marking of entries, excerption, determination of equivalents for individual entries, determination of alphabetical principles, alphabetical order of cards, the semantic study of the card index, the distinction of homonyms, finding synonyms, completion of pronunciation and grammar data, choice of lexicographic abbreviations and symbols, review and correction procedure and the last phase is the final formulation.

Some authors define parts of the lexicographic process in general (Wiegand et al., 2010; Cabre, 1993), others focus exclusively on the creation of monolingual dictionaries (Stoffova and Stoffa, 2011) or the creation of bilingual dictionaries (Pique-Angordans and Posteguillo, 2007; Oplatek , 2007). The subject of other works is the creation of exclusively multilingual specialized dictionaries (Fordosova et al., 2019).

The process of creating dictionaries can also be viewed in terms of the dichotomy of printed dictionaries - online dictionaries. A large part of lexicographic works deals with printed dictionaries, but in recent years the authors' attention has gradually 
shifted to internet dictionaries, e.g. A. Klosa (2009) focuses on details of computerlexicographical process for online dictionaries under construction. P.A. FuertesOlivera and S. Tarp (2014), in their monograph "Theory and Practice of Specialized Online Dictionaries" transfer from general lexicographical theory through the general theory of specialized dictionaries to special problems related to online dictionaries, including their making, designing and updating. On the other hand, H.E. Wiegand (1998) reflects and analyses in detail both printed and online types of dictionaries.

Another important aspect of the lexicographic process in bilingual dictionaries is the question in which direction to proceed when searching for equivalents - from a foreign language to the mother tongue or vice versa. In universally formulated descriptions of the lexicographic process in general, the authors do not usually address this issue. For example, H.E. Wiegand (1998) does not mention in which language they should be created when dealing with the selection of primary sources and the compilation of the initial database, and the processing of the intermediate database. The same applies to the description of the lexicographic process of creating bilingual and multilingual dictionaries provided by M.T. Cabré.

However, in some works focused on the creation of bilingual dictionaries, this aspect is more often reflected. However, it cannot be generalized to all authors engaged in the creation of bilingual dictionaries. For example, A. Tihelková (2006) in her work "Theory and Practice of Czech Bilingual Specialized Dictionaries" talks about two parallel text corpora in general, and A. Klosa (2009) does not dwell on the question of what language should be preferred for primary texts when describing the phase of data acquisition.

On the other hand, there are lexicographers and authors of bilingual dictionaries at the same time who explicitly appeal to the fact that the target language should be the mother tongue. "When creating a bilingual dictionary, if possible, we follow the same general rule as in translation: original - translation = foreign language - native language. Thus, we first collect foreign language material, to which we assign equivalents in the native language. This method is usually easier, faster and often more accurate for the terminography." (Oplatek, 2007: 5)

This opinion is also reflected in the description of the creation of a bilingual dictionary by R. Kocourek (1966). He even proposes to translate the entire source texts into the mother tongue, then have them assessed by several experts (this phase is referred as an equivalence survey) and only then to use these translated and corrected texts to determine entries in the planned dictionary and extract individual equivalents. Although the author acknowledges that the described method is particularly laborious, he highlights its strengths, which could be summarized as correctness, relative completeness of the acquired vocabulary, and verifiability of the excerpted data. R. Kocourek (1966: 81-82) is convinced that "the method purposefully aims to determine the correct equivalents, which are probably the most important criterion for the value of the dictionary."

Although we agree with this opinion, the given procedure for creating a multilingual dictionary is not always applicable. In the case of the six-language vocabulary, it was not feasible for several reasons:

- Diversity of the author team - in the case of multilingual dictionaries, individual authors are experts in various foreign languages. The language that all members of the author team speak at a high level is usually their common mother tongue. For this reason, the mother tongue had to be the source text.

- Personnel and financial standpoint - from this point of view, it would be very difficult to translate the whole source texts and find specialists hippologists for all six language mutations which will be able to proofread the whole texts (especially in the case of the so-called "small languages").

XLinguae, Volume 14 Issue 2, April 2021, ISSN 1337-8384, eISSN 2453-711X 
- The nature of primary sources for the extraction of terms - this criterion cannot be generalized to create all multilingual dictionaries, but in our case, the dictionary was a response to the needs of colleagues and students of the SUA, and the compilation of entries was based on their study and working materials. The language of the primary sources was exclusively Slovak.

Based on the synthesis of theoretical knowledge gained from the study of these lexicographic sources and own practical experience in creating the "Slovak-EnglishFrench-German-Russian-Spanish dictionary of hippology", we divide the elaboration of the specialized bilingual dictionaries into the following phases:

1. Conception

2. Extraction

3. Identification of equivalents

4. Verification

5. Finalization

\section{Conception}

The transition from the original idea to creating the dictionary represents the preparatory phase of the lexicographic process. Although the preparation of the concept may seem trivial at first glance, it is a significant step in shaping the whole process that follows. It is essential to set the basic starting points. Theoretical discussions do not mention a list of all possible starting points. Therefore, we decided to summarize them in the following sentence:

Who conveys what, to whom, how, in which languages, through what medium, when, at what price, on the basis of what data, and to what extent?

WHO? Creating a team of authors consisting of linguists and specialists in the particular subject field as consultants, in the case of online dictionaries, an IT specialist will be included.

WHAT? Determination of the subject field, delimitation of thematic areas + acquisition of basic knowledge of the subject field, ideally, in the mother tongue as well as in foreign languages in which the specific professional work will be carried out.

TO WHOM? Analysis of the needs of the recipient/addressee - requirements and expectations of the target group.

HOW? Study and analysis of theoretical resources - studying basic information about methods and processes related to a specialized lexicography

IN WHICH LANGUAGES? Determining the number of languages and their concretization based on the needs of the addressee and the possibilities of the author team.

WHAT MEDIA? Determining the type of dictionary - bilingual vs. multilingual, general vs. specialized, printed vs. online etc.

WHEN? Determining the time schedule for each phase of the dictionary creation.

AT WHAT PRICE? Establishment of an approximate financial budget. 
ON THE BASIS OF WHICH DATA? Selection of appropriate resources for the extraction of terms - text corpus representing the selected thematic areas from the given field.

TO WHAT EXTENT? Determining the extent of the dictionary - the approximate number of terms.

In the conceptual phase of creating a multilingual specialized dictionary, usually only specialized texts in the source language are determined for the extraction of terms that will present the list of entries of the planned dictionary. At this stage, we do not consider it necessary to have a clear idea of the text corpus in the target language, which will be used for searching and verifying the foreign language equivalents.

However, both types of resources should meet certain criteria. Based on our experience, we consider the following criteria to be important: 1. expertise, 2 . representativeness, and reliability (the author is a recognized authority in the given field), 3. complexity (selected texts cover several areas of the field), 4. timeliness, 5. originality (source texts are not translations but original texts in the source language).

As to the requirement of timeliness, we have included it among the main criteria for the elimination of outdated terms. Jurčáčková (2002) also states in her publication "Terminology: basic principles, methods and their application" that in the case of older documents, the terminology may not be reliable. However, we recognize that some scientific disciplines may be exceptions where, in contrast to dynamically developing disciplines such as Economics, there is no such frequent creation of neologisms. This is supported by S. Oplatek (2007), who states that in creating the archaeological dictionary it was necessary for him to use older sources.

Although many lexicographic resources state that primary sources can be in printed, oral and online form (e.g. Cabre, 1993; Tihelkova, 2006; Oplatek, 2007) and that "among the main types of sources to be considered, belong legally binding documents (laws, recommendations, standards), documents generally recognized by the scientific community (textbooks, dissertations, scientific journals), common but not always generally accepted materials (brochures, instructions for use, lists of parts of materials, reports, etc.), human resources (members of the working group and other experts), terminological databases, terminological dictionaries, monolingual dictionaries and encyclopedias "(Jurcackova, 2002: 33), we consider specialized texts in printed form as the main sources. Specifically, in the case of the multilingual specialized dictionary of hippology, these were study materials recommended at the bachelor's study program hippology at the SUA in Nitra.

When choosing primary sources, we do not focus only on the selection of sources intended for the extraction of terminological units. Although this is often not mentioned in theoretical resources, when choosing terms and especially later when looking for their foreign language equivalents, it is sometimes necessary to reach for additional specialized materials in the source language. These are used by the author team to clarify the exact meanings of specialized vocabulary. R. Kocourek (1966) calls them semantic terminological sources and distinguishes between definitional (e.g. norms) and illustrative (diagrams, photographs, tables, etc.) sources.

\section{Extraction}

The aim of the second phase is to build a lexicographic database in the source language. This is done on the basis of an analysis of primary sources, which were determined in the conceptual phase. H. E. Wiegand (1998) recommends designing the database so that it can also be used to create other dictionaries.

A well-elaborated concept at the beginning of the lexicographic process will also be reflected in the excerption of terminological units. It is important to pay attention to

XLinguae, Volume 14 Issue 2, April 2021, ISSN 1337-8384, eISSN 2453-711X 
the even representation of terms from different sub-areas of the subject field in question. When the members of the author team study and analyze materials on the given field in the first phase, it is easier for them to analyze the primary texts, extract terminological units and cover the basic vocabulary from the whole field. As there is no rule on which terms to extract, we recommend following the frequency of occurrence of the terms in primary texts and the advice of specialists in the given field.

The subject area diagram with tree structure can be a great help in maintaining the proportionality, as all thematic areas that the extracted terms should cover are clearly visualized. In the case of a multilingual dictionary of hippology, the subject area tree had the following structure:

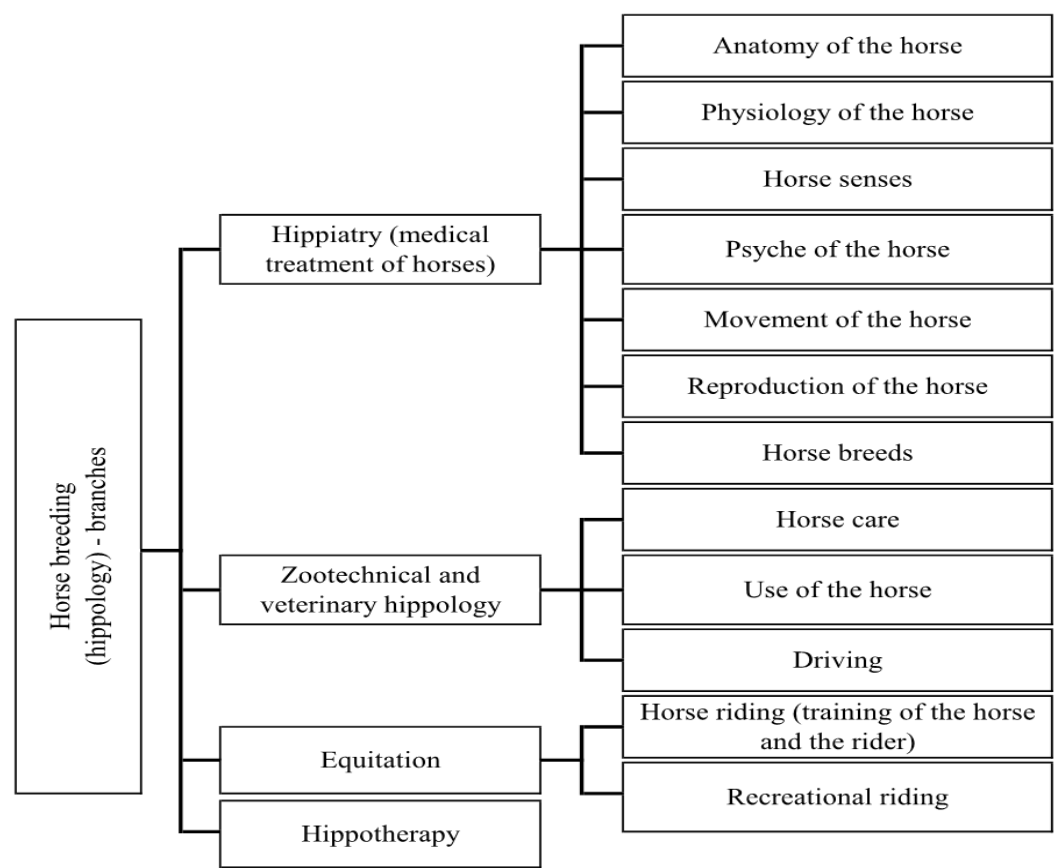

\section{Figure 2: The subject area diagram with tree structure applied in the elaboration of a multilingual specialized dictionary of hippology (Fordosova et al., 2020: 39).}

An elaboration of the concept structure is strongly recommended by M. T. Cabré (1993: 300), who considers the following characteristics to be essential for a wellelaborated concept structure:

1. it must encompass the entire subject field in question;

2. it must include all the structured branches of the subject field you want to cover;

3. it must present the relations that exist between the different branches and those existing inside each of them;

4. it must not include irrelevant concepts nor non-productive concepts, i.e. such concepts that do not lead to a set of concepts (and designations that materialize them).

5. it must be structured in such a way that the same concept is not found in different branches of the subject field in question. 
Structuring a subject field is very useful because it facilitates the delimitation of the field, since each of its parts must be specified and related to the whole, as well as the classification and treatment of terminological units. It constitutes a plan for the extraction of terminological units, i.e. specialized materials related to different subfields, which will constitute the corpus for the extraction of terms.

In older publications, it is recommended to establish a card index at this stage and to record each excerpted term with the relevant information on one card. However, at present, this work is carried out with the help of electronic databases. The big advantage is the sharing of files on the Internet in the cloud (e.g. GoogleDisk, OneDrive, Dropbox), which allows the access to the current version of the database to all members of the author team simultaneously from any PC. In our case, the extracted terms were recorded in an Excel file and shared on GoogleDisk.

When creating a list of entries in the source language, the terms are recorded in the canonical form. A great help in the future assignment of foreign language equivalents will be if the context or a part of the text specifying the term is recorded as well.

In the final phase of completing the database in the source language, it is necessary to involve specialists in a given field. They will check extracted expressions, comment on their validity and evaluate the balance, relative completeness, and usability of the corpus. After a subsequent completion or removal of recommended expressions, the basic corpus is verified by a linguist - expert in a given language. To illustrate, we will list the changes that were needed to be made in the case of a multilingual dictionary of hippology. A Slavicist removed several bohemisms that appeared in the source texts (e.g. závody instead of preteky). Concerning doublets, she determined which pairs of expressions are semantically different (nitkové papily - nitkovité papily) and which can be understood as semantic variants (jarmová kost' - lícna kost'). Based on our own experience, in this phase of the creation of the dictionary, we do not recommend sorting the list of entries or database alphabetically. It is more practical to keep the vocabulary in the thematic units according to the sub-areas of the given subject field they have been extracted from. This will greatly facilitate the work of other members of the author team in the next phase of the elaboration of the dictionary.

\section{Identification of equivalents}

After determining the final version of the corpus in the source language, the assignment of foreign language equivalents to the given terms in Slovak begins. This work consists not only in searching and consulting other specialized dictionaries and online databases but also in the study of specialized texts. We will use the conceptual apparatus of translation and label them as parallel texts, i.e. texts that were created as original in the target language and are thematically, functionally, and stylistically similar to the source text.

The main goal of identifying equivalents is to find direct language equivalents that would match in all expression characters. If it is not possible to maintain the denotative equivalence, we look for the functional language equivalents in parallel texts. This, however, is not desirable with regard to specialized dictionaries.

In lexicographic studies, usually, three degrees of equivalence are mentioned: full equivalence, partial equivalence, and zero equivalence (e.g. Bergenholtz and Tarp 1995; Tihelkova, 2006). They are also analyzed by E. H. Klapicová (2005), who focuses on the description of a symmetric and asymmetric equivalence and the combination of both of them. A more detailed classification is presented by the linguist W. Koller (2001), who divides the partial equivalence into three further categories. The results of such a division are the following five variants: 
a) One-to-one correspondence: one term in the source language corresponds to one equivalent in the target language

\begin{tabular}{|c|c|}
\hline Ger. Mähne & $\rightarrow$ Span. crin \\
\hline Eng. stallion & $\rightarrow$ Ger. Hengst
\end{tabular}

Figure 3: Examples on one-to-one correspondence (own work)

\section{b) One-to-many correspondence}

Diversification: several equivalents in the target language correspond to one term in the source language

Slk. žriebä

Eng. foal (equine up to one year old)

Eng. colt (male horse under the age of 4)

Figure 4: Example on one-to-many correspondence (own work)

c) Many-to-one correspondence

Neutralization: several terms in the source language correspond to one term in the target language

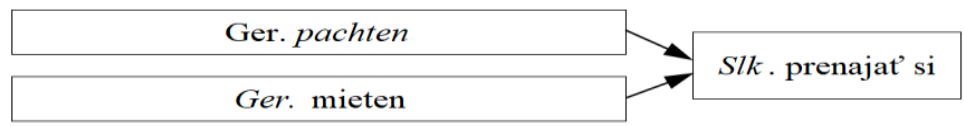

Figure 5: Example on many-to-one correspondence (own work)

d) One-to-partial correspondence: the term in the target language only partially matches the term in the source language

Ger. Geist $\rightarrow$ Eng. mind (+ intellect, intelligence, thinking faculty, spirit)

Figure 6: Example on one-to-part correspondence (own work)

e) One-to-zero correspondence: no direct equivalent in the target language corresponds to the term in the source language

Ger. Gauleiter $\rightarrow S l k$. no equivalent

Figure 7: Example on one-to-zero equivalence (own work)

The approach to equivalence varies depending on whether a general or specialized dictionary is created. Concerning general dictionaries, partial equivalence prevails, and full equivalence is considered to be rare to occur. On the other hand, as one of the principal characteristics of terms is their precise meaning, "anything less than full equivalence is undesirable in specialized dictionaries."(Tihelkova, 2006: 30). However, the above-presented examples on equivalence show that it is not always possible to reach full equivalence.

At the beginning of the phase of identifying equivalents, it is important to determine the final microstructure of the dictionary, i.e. the exact structure of the entry and the type of additional information presented for each entry. Detailed information (not 
only of morpho-syntactic nature) is expected to be found in monolingual dictionaries. One of the most detailed microstructural records is described by Levická (2006: 112). She completed the Rey's model (1979: 99), which consists of the following parts and subparts:

1. linguistic part - a) morpho-syntax: entry, grammatical category, phonetics, variants, synonyms, and valency; b) sociological/pragmatic information - notes on the use of the term on a horizontal or vertical level, normative notes, frequency, context, collocations, and exemplification;

2. conceptual and semantic part - a) affiliation to the thematic area and use; b) definition, or suggestions for another term with better motivation; c) picture, graph; correlation with other terms within the same subject field; d) foreign language equivalent (s), variants;

3. documentation part - a) bibliographic record of contexts, definitions, equivalents etc.; b) author of the entry and date, code of the entry within the whole subject field.

Bilingual and multilingual dictionaries present a much simpler microstructure. Its specific content depends on the decision of the authors themselves but is usually limited to the indication of basic grammatical categories. In the case of specialized dictionaries, phonetic characteristics are not usually mentioned either. The inclusion of collocations as a part of its description also depends on the authors' consideration. H. Bergenholtz and S. Tarp (1995: 123) recommend taking into account two factors: "intended dictionary functions and user competence".

\begin{tabular}{|l|c|c|c|c|}
\cline { 2 - 5 } \multicolumn{1}{c|}{} & $\begin{array}{c}\text { USER TYPE 1 } \\
\text { low level of } \\
\text { both encycl. } \\
\text { and } \\
\text { foreign- } \\
\text { language } \\
\text { competence }\end{array}$ & $\begin{array}{c}\text { USER TYPE 2 } \\
\text { low level of } \\
\text { encycl. and } \\
\text { high level of } \\
\text { foreign- } \\
\text { language } \\
\text { competence }\end{array}$ & $\begin{array}{c}\text { USER TYPE 3 } \\
\text { high level of } \\
\text { encycl. and } \\
\text { low level of } \\
\text { foreign- } \\
\text { language } \\
\text { competence }\end{array}$ & $\begin{array}{c}\text { USER TYPE 4 } \\
\text { high level of } \\
\text { both encycl. } \\
\text { and } \\
\text { foreign- } \\
\text { language } \\
\text { competence }\end{array}$ \\
\hline Reception of $\mathrm{L}_{1}$ & few & few & - & - \\
\hline Production in $\mathrm{L}_{1}$ & (many) & (many) & fewer & fewer \\
\hline Translation $\mathrm{L}_{1}-\mathrm{L}_{2}$ & (many) & many & many & fewer / many \\
\hline Translation $\mathrm{L}_{2}-\mathrm{L}_{1}$ & many & many & many & fewer / many \\
\hline Reception of $\mathrm{L}_{2}$ & few & few & few & $-/$ few \\
\hline Production in $\mathrm{L}_{2}$ & (many) & (many) & many & fewer / many \\
\hline
\end{tabular}

\section{Figure 8: The need for collocations on the basis of user types and dictionary functions (Bergenholtz and Tarp, 1995: 123)}

The complete absence of additional information in specialized dictionaries is not perceived positively. As A. Tihelková (2006: 22) states: "The dictionary, otherwise excellent from the terminological point of view, fails to give any information on grammar or use. However, Czech users producing texts in English would greatly benefit from the inclusion of grammar". R. Kocourek (1966) also shares this opinion. $\mathrm{He}$ is convinced that the reader will also welcome the clarification of grammatical data (2020) in a specialized dictionary. Moreover, he recommends stating the correct pronunciation in specialized dictionaries as well. R. Kocourek's opinion is supported by M. Šemelík, who claims that phonological transcription, or at least the indication of the word accent, should be included in bilingual dictionaries. 
As to the structure of the entry in a multilingual specialized dictionary of hippology, for pragmatic reasons, we decided to present only basic grammatical categories in the form of a simple microstructure (for other types of microstructures - integrated, nonintegrated, extended, and complex - see P. Sutter (2017)). Namely, we included the grammatical category of the gender in nouns and the grammatical category of the number for nouns mainly used in the plural. We assumed that the future users of the multilingual dictionary of hippology (especially students and colleagues from the university) would already have basic knowledge of the particular language.

The choice of lexicographic abbreviations is also related to the type of grammatical categories, which also needs to be discussed at this stage. In the case of multilingual dictionaries, we definitely recommend using Latin abbreviations (e.g. for the gender: $m, f, n)$.

\section{Verification}

After creating the corpora with the appropriate equivalents in individual languages, it is necessary to again ask the specialists for cooperation and consult with them about their content. At the same time, verification of concepts in individual national language corpora and terminological databases takes place.

Another task to be done consists of determining the macrostructure of the dictionary, i.e. setting the principle of arranging individual entries. In general, one can proceed on the basis of two main principles - arrange entries alphabetically or conceptually. With the alphabetical macrostructure of the dictionary, we are automatically reminded of the initial alphabetic order, which is used most often in practice. If all entries are sorted according to the access alphabet, this is called a strict-alphabetical macrostructure. Every terminological unit may be introduced as an individual dictionary entry or as a part of an entry block consisting of several entries (niching and nesting). In the latter case, the headwords of such groupings are called entrance lemmas, and are arranged alphabetically. Other lemmas within an entry block are called sublemas, and can follow the strict-alphabetical order (niching), or may deviate from the strict-alphabetical order (nesting). If the sublemas are not arranged alphabetically, we deal with the non-strict-alphabetical macrostructure (Sutter, 2017). When deciding on the macrostructure of a multilingual dictionary of hippology, we abandoned the idea of using niching or nesting macrostructure. Although the arrangement of lemmas in word families would be beneficial for the target users, due to the high number of language corpora that would need to be synchronized, we opted for an alphabetical arrangement of individual lemmas.

Another problem to be solved was related to the introduction of synonyms within the dictionary. To make it easier for users to work with the dictionary, the author team decided to list synonyms in parentheses after the headword. Every synonym is also listed as a separate headword following the alphabetical order. Moreover, to clarify the meaning of some terms, an additional explanation in italics is given in parentheses (Figure 9).

\begin{tabular}{|l|l|}
\hline Lendenwirbel $m($ syn Lumbalwirbel $m)$ & bedrový stavec $m$ \\
\hline Ligamente $n p l(s y n$ Bänder $n p l)$ & väzy m pl (väzivo, tkanivo) \\
\hline Linse $f$ & šošovka $f($ na oku $)$ \\
\hline Liverpool-Hinderniss $n$ & prekážka $f$ Liverpool \\
\hline Lob $n$ & pochvala $f$ \\
\hline longieren & lonžovat \\
\hline Lumbalwirbel $m($ syn Lendenwirbel $m)$ & bedrový stavec $m$ \\
\hline
\end{tabular}


Figure 9: Introduction of synonyms in a multilingual specialized dictionary of hippology (own work)

\section{Finalization}

Although the core of the lexicographic work has already been carried out (the corpus in a source language is compiled, foreign language equivalents are assigned, and all terminological units are verified), the creation of the dictionary is not over yet. In the last phase, it is necessary to give the final lexicographic database the form of a dictionary.

In the case of a printed dictionary, the design and the appropriate size are to be consulted with a graphic designer. The layout of the page and mainly its orientation (portrait vs. landscape) must be taken into account, particularly with regard to multilingual dictionaries (e.g. if we wanted all six languages to fit on the double-page spread, the only possible solution for us was a landscape orientation of the page). While the graphic designer deals with the graphic design of the dictionary and the cover, the authors prepare other components of the dictionary.

The mandatory parts of the print dictionary are functional/structural components. Some of them can be understood as separate text units (e.g. Foreword). Their exact number and type depend on the decision of the authors, the type of dictionary, and the tradition.

Depending on their position in the dictionary, we distinguish between front matter (structural components located before the word list) and back matter (structural components located after the word list). Together they form frame texts for the core of the dictionary. From this aspect, word lists are then referred to as inner texts (Wiegand, 2010).

Structural components of the multilingual specialized dictionary forming front matter of the dictionary can be the following ones (if a six-language specialized dictionary is taken as an example):

a) Introductory page with the names of the members of the author team and reviewers

b) Contents

c) Foreword/Preface

d) Instructions on how to use the dictionary

e) List of symbols and abbreviations

Inner text is a corpus of technical terms in 6 languages.

An essential part of the back matter of the texts consists of:

a) Glossaries - in alphabetical order for each language separately

b) Bibliographic references

After completing all the necessary functional components, approving the cover, and after the last thorough control of the final version of the dictionary, the dictionary is submitted for printing procedure. This closes the lexicographic process.

\section{Conclusion}

Specialized lexicography is an applied scientific discipline that continuously builds and improves its theory. Lexicographic work ought to be approached systematically. It is appropriate to divide the work into several phases, set realistic goals, and strictly follow established methodological principles.

The presented study offers a detailed description of the creation of specialized dictionaries. It is based on the analysis of theoretical studies on the lexicographic process and their comparison with our own practical experience concerning the elaboration of a specialized dictionary. The research is focused on multilingual dictionaries as their elaboration is specific in several respects. However, several authors are convinced that it is necessary to proceed from a foreign language to the mother tongue when creating bilingual dictionaries. However, in the case of

XLinguae, Volume 14 Issue 2, April 2021, ISSN 1337-8384, eISSN 2453-711X 
multilingual dictionaries, the opposite procedure is also logical. In addition, we point out the fact that the microstructure of the multilingual dictionary is usually a simple one despite that the general lexicographic publications usually recommend to provide users with as much information as possible. However, in practice, the information on dictionary entry usually decreases in proportion to the increasing number of languages.

The description of individual phases is supplemented by practical recommendations. For example, when extracting terms from the source texts, we recommend recording the context or a part of the text that would specify the term. This will be very helpful for the members of the author team when assigning foreign language equivalents to Slovak terms. In the case of multilingual dictionaries, not all authors participate in the compilation of the corpus in the source language. Thus, they may deal with a particular term for the first time when searching for the equivalents in a specific target language.

Moreover, the authors will find it easier to find equivalents if the database in the source language is not sorted alphabetically at the end of the extraction phase. We recommend keeping it in the thematic units or blocks in which it occurred in the primary sources. There is a certain probability that it will also appear in a similar way in parallel texts in the target languages.

A prerequisite for an excellent specialized dictionary is the cooperation between the members of the author team and the specialists in a given subject field, who speak the source language and, ideally, the target language as well. Cooperation is essential, particularly in consulting the appropriateness of including the terms and their foreign language equivalents into the dictionary. When implementing larger projects, the subject-field specialists should be members of the author team.

\section{Bibliographic references}

BERGENHOLTZ, H. - TARP, S. 1995. Manual of Specialised Lexicography: the preparation of specialised dictionaries. Amsterdam: John Benjamins Publishing. ISBN 9027216126.

BERGENHOLTZ, H. - TARP, S. 2003. Two opposing theories: On H.E. Wiegand's recent discovery flexicographic functions. In: Hermes, Journal of Linguistics, n. 31, pp. 171-196. Available online: http://netdob.asb.dk/Lit/Hermes/H3Lll.pdf

BESHARAT, F. 2014. Experts and Specialized Lexicography: perspectives and needs. In: Terminàlia, n. 9., pp. 12-21. ISSN 2013-6706. Available online: http://terminalia.iec.cat

CABRE, M. T. 1993. La terminologia. Teoria, metodologia, aplicaciones. Barcelona: Editorial Antartida/Empuries. ISBN 8475964052.

CABRE, M. T. 1999. Terminology: theory methods and applications. Amsterdam/Philadelphia: John Benjamins Publishing Company. ISBN 9027216339.

FELBER, H. 1986. Vseobecna teoria terminologie. In: Kultura slova, vol. 20, n. 5, pp. 129-135.

FORDOSOVA, M. - PRIDAVKOVA, V. - HOLUBEKOVA, A. 2020. Uskalia tvorby viacjazycneho hipologickeho slovnika. In Od textu k prekladu 13. Banska Bystrica: Belianum, pp. 33-47. ISBN 978-80-557-1704-3

FUENTES-OLIVERA, P.A. - TARP, S. 2014. Theory and Practice of Specialised Online Dictionaries. Berlin/Boston: de Gruyter Verlag. ISBN 9783110348835.

HALO, M. - KOVALCIK, E. 2003. Popis exterieru koni. 1. vyd. Nitra : Slovenska polnohospodarska univerzita. ISBN 8080691541.

JURCACKOVA, Z. 2002. Terminologia: zakladne zasady, metody a ich aplikacia. Bratislava: Centrum vedecko-technickych informacii SR. ISBN 8085165856.

KLAPICOVA E. H., 2005. Stavba hesla v dvojjazycnom slovniku a jeho parametre. In Studi Slavistici, II, pp. 219-235. ISSN 1824-7601. 
KLOSA, A. 2009. The lexicographical process: online dictionaries. Available online: http://multimedia.ids-

mannheim.de/mediawiki/web/images/6/6b/Klosa_LexicographicalProcess_Preprint.p df

KOCOUREK, R. 1966. K metode zpracovani dvoujazycneho odborneho slovniku. In Ceskoslovensky terminologicky casopis, vol. V, n. 2.

KOLLER, W. 2001. Eine Einfuehrung in die Uebersetzungswissenschaft. Wiebelsheim: Quelle und Meyer Verlag. ISBN-10: 3494013799

LANDAU, S. L. 1984. Dictionaries. The Art and Craft of Lexicography. New York: Charles Scribner's Sons.

LEVICKA, J. 2006. Terminologicke implikacie strukturnej a kontextovej analyzy francuzskej a slovenskej stavebnej lexiky: dizertacna praca. Bratislava: Univerzita Komenskeho.

MASAR, I. 2000. Ako pomenuvame v slovencine: Kapitolky z terminologickej teorie a praxe. Bratislava: SJS pri SAV. ISBN 8096757490.

MISTRIK, J. et al. 1993. Encyklopedia jazykovedy. 1. vyd. Bratislava: Obzor. ISBN 8021502509.

NIELSEN, S. 1999. Mediostructures in bilingual specialized dictionaries. In: Lexicographica, Tübingen In: Max Niemeyer. vol. 15, pp. 90-113. ISBN 0175-6206.

OPLATEK, S. 2007. Terminograficka prace a terminograficke prameny. In Slavica Iuvenum VIII, pp. 33-40. ISBN 978-80-7368-407-5

PIQUE-ANGORDANS, J. - POSTEGUILLO GOMEZ, S. 2007. Specialized dictionaries and corpus linguistics in the translation of computer technology. In: Problemas linguisticos en la traduccion especializada. Valladolid: Secretariado de Publicaciones e Intercambio Editorial, pp. 87-108. ISBN 9788484484141. Available online: https://www.uv.es/piquej/Pique-Posteguillo_SpecialisedDictionaries-web.pdf STOFFOVA, V. - STOFFA, J. 2011. Tvorba elektronickych terminologickych slovnikov. In: Technologie vzdelavania v priprave ucitelov prirodovednych a technickych odborov: zbornik $\mathrm{z}$ medzinarodnej vedecko-odbornej konferencie. Presov: Presovska univerzita v Presove, pp. 325-333. ISBN 978805550438. Available online: http://fyzika.unipo.sk/wp-content/files/konferencia2011/papers/140.pdf

SUTTER, P. 2017. Diatopische Variation im Wörterbuch. Berlin, Boston: de Gruyter Verlag. ISBN: 9783110479973.

SEMELIK, M. 2020. Nekolik poznamek ke zpracovani slovotvornych elementu v prekladovem slovniku. In: Casopis pro moderni filologii, 102, 1, pp. 102-117. ISSN 0008-7386

TIHELKOVA, A. 2006. Theory and Practise of Czech Bilingual Specialized Dictionaries: Disertacni prace. Prague: Univerzita Karlova v Praze. Available online: https://is.cuni.cz/webapps/zzp/detail/24363

WIEGAND, H. E. 1988. Was eigentlich is Fachlexikographie? Mit Hinweisen zum Verhaltnis von sprachlichem und enzyklopadischem Wissen In: Deutscher Wortschatz. Lexikologishce Studien. Ludwig Erich Schmitt zum 80. Geburtstag von seinen Marburger SchUlern, ed. H.H. Munske et. al. Berlin/New York: de Gruyter. pp. 729-790,

WIEGAND, H. E. 1998. Woerterbuchforschung. Untersuchungen zur Woerterbuchbenutzung, zur Theorie, Geschichte, Kritik und Automatisierung der Lexikographie. 1. Teilband. Berlin: de Gruyter Verlag. ISBN: 3110135841

WIEGAND, H. E. et al. 2010. Worterbuch zur Lexikographie und Worterbuchforschung. Systematische Einfuhrung A-C. Berlin/New York: Walter de Gruyter. ISBN 9783110164725.

Words: 7788

Characters: 52769 (29,32 standard pages)

XLinguae, Volume 14 Issue 2, April 2021, ISSN 1337-8384, eISSN 2453-711X 
Mgr. Stanislava Gálová, PhD.

Department of Languages

Slovak University of Agriculture in Nitra

Tr. A. Hlinku 2

94976 Nitra

Slovakia

stanislava.galova@uniag.sk

Mgr. Katarína Klimentová, PhD.

Department of Languages

Slovak University of Agriculture in Nitra

Tr. A. Hlinku 2

94976 Nitra

Slovakia

katarina.klimentova@uniag.sk

PaedDr. L'ubomíra Moravcová, PhD.

Department of Languages

Slovak University of Agriculture in Nitra

Tr. A. Hlinku 2

94976 Nitra

Slovakia

lubomira.moravcova@uniag.sk 